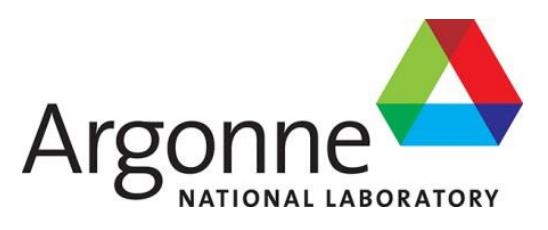

ANL-19/38

\title{
PTT System Performance Evaluation in 3-D Imaging of AM Components
}

Pulsed Thermal Tomography Nondestructive Examination of Additively Manufactured Reactor Materials and Components

Nuclear Science and Engineering Division 


\title{
About Argonne National Laboratory
}

Argonne is a U.S. Department of Energy laboratory managed by UChicago Argonne, LLC under contract DE-AC02-06CH11357. The Laboratory's main facility is outside Chicago, at 9700 South Cass Avenue, Argonne, Illinois 60439. For information about Argonne and its pioneering science and technology programs, see www.anl.gov.

\section{Document availability}

Online Access: U.S. Department of Energy (DOE) reports produced after 1991 and a growing number of pre-1991 documents are available free at OSTI.GOV (http://www.osti.gov/), a service of the U.S. Dept. of Energy's Office of Scientific and Technical Information

\author{
Reports not in digital format may be purchased by the public from the \\ National Technical Information Service (NTIS): \\ U.S. Department of Commerce \\ National Technical Information Service \\ 5301 Shawnee Rd \\ Alexandria, VA 22312 \\ www.ntis.gov \\ Phone: (800) 553-NTIS (6847) or (703) 605-6000 \\ Fax: (703) 605-6900 \\ Email: orders@ntis.gov
}

\section{Reports not in digital format are available to DOE and DOE contractors from the Office of Scientific and Technical Information (OSTI):}

U.S. Department of Energy

Office of Scientific and Technical Information

P.O. Box 62

Oak Ridge, TN 37831-0062

www.osti.gov

Phone: (865) 576-8401

Fax: (865) 576-5728

Email: reports@osti.gov

This report was prepared as an account of work sponsored by an agency of the United States Government. Neither the United States Government nor any agency thereof, nor UChicago Argonne, LLC, nor any of their employees or officers, makes any warranty, express or implied, or assumes any legal liability or responsibility for the accuracy, completeness, or usefulness of any information, apparatus, product, or process disclosed, or represents that its use would not infringe privately owned rights. Reference herein to any specific commercial product, process, or service by trade name, trademark, manufacturer, or otherwise, does not necessarily constitute or imply its endorsement, recommendation, or favoring by the United States Government or any agency thereof. The views and opinions of document authors expressed herein do not necessarily state or reflect those of the United States Government or any agency thereof, Argonne National Laboratory, or UChicago Argonne, LLC. 


\section{PTT System Performance Evaluation in 3-D Imaging of AM Components}

\section{Pulsed Thermal Tomography Nondestructive Examination of Additively Manufactured Reactor Materials and Components}

prepared by

Alexander Heifetz ${ }^{1}$, Thomas W. Elmer ${ }^{1}$, Xin Zhang ${ }^{1,2}$, Jafar Saniie ${ }^{2}$

${ }^{1}$ Nuclear Science Engineering Division, Argonne National Laboratory

${ }^{2}$ Department of Electrical and Computer Engineering, Illinois Institute of Technology, Chicago, IL

September 16, 2019 


\section{Table of Contents}

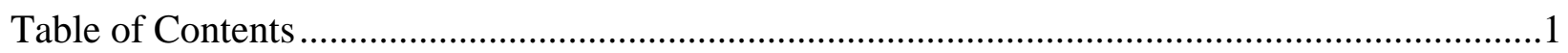

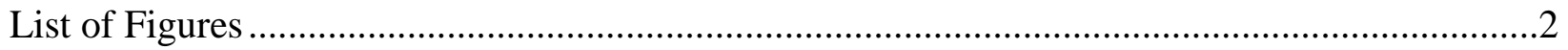

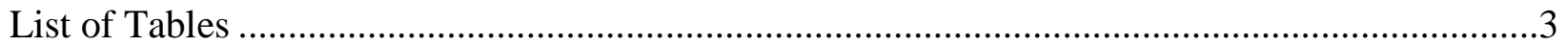

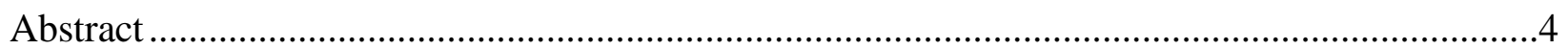

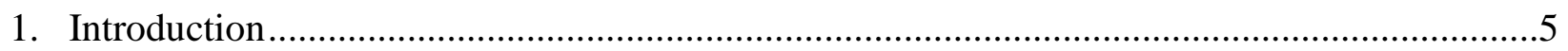

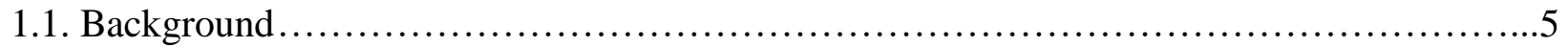

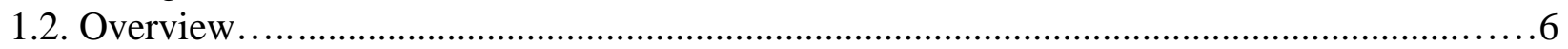

2. Imaging of Additively Manufactured Structures with Complex Geometry ............................7

2.1. Pulsed Thermal Tomography System Upgrade ................................................................. 7

2.3. Imaging Additively Manufactured IN718 Nozzle Plate ....................................................9

2.4. Imaging Additively Manufactured IN718 Particle Filter Plate ..........................................11

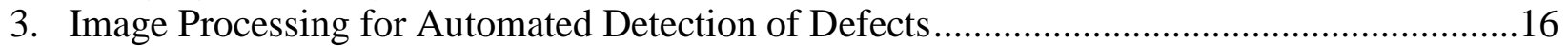

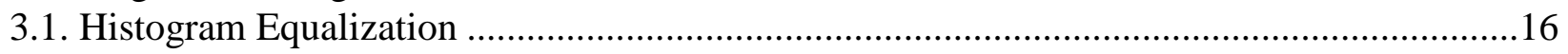

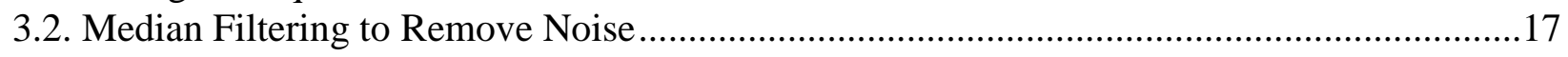

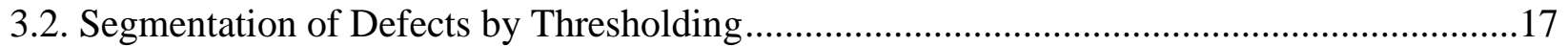

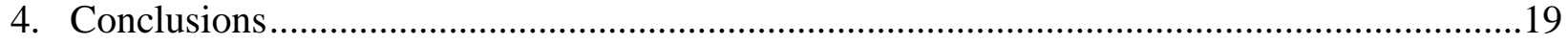

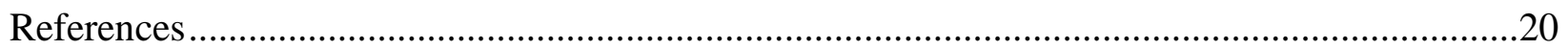




\section{List of Figures}

Figure 1 - Schematic diagram of pulsed thermal tomography system ................................... 6

Figure 2 - Screenshot of GUI for converting output of Research IR software to match file requirements of effusivity reconstruction code............................................................... 8 Figure 3 - Photograph of PTT setup imaging of IN718 nozzle plate with new FLIR X8500sc

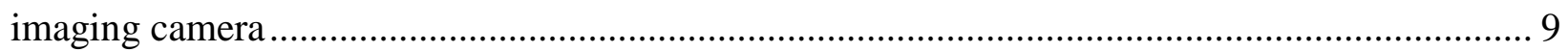

Figure 4 - (a) Photograph of the IN718 nozzle plate (b) Highlighted area imaged with PTT ....... 9 Figure 5 - Reconstruction of parallel slices of IN718 nozzle plate at $0.67 \mathrm{~mm}, 1 \mathrm{~mm}, 1.2 \mathrm{~mm}$, and $1.35 \mathrm{~mm}$ depths ............................................................................................................ 10

Figure 6 - Reconstruction of 3-D effusivity of IN718 nozzle plate (Left) Parallel slice at 1.35mm depth (Right) Vertical cross-section slices 11

Figure 7 - Photograph of PTT laboratory setup for imaging of IN718 particle filter plate with new

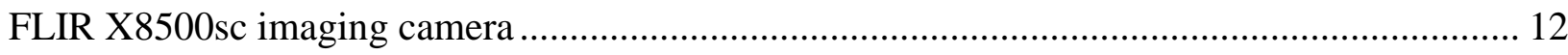

Figure 8 - Photograph of the filter plate (a) top view (b) bottom/side view ............................. 12 Figure 9 - Reconstruction of parallel slices of IN718 particle filter plate top face at estimated $1 \mathrm{~mm}$, $1.35 \mathrm{~mm}, 1.65 \mathrm{~mm}$, and $1.9 \mathrm{~mm}$ depths....................................................................... 13

Figure 10 - Reconstruction of 3-D effusivity of IN718 filter plate (Left) Parallel slice at 1.9mm depth (Right) Vertical cross-section slices ................................................................... 14 Figure 11 - Reconstruction of parallel slices of IN718 particle filter plate side face at estimated $0.75 \mathrm{~mm}, 0.9 \mathrm{~mm}, 1.1 \mathrm{~mm}$, and $1.3 \mathrm{~mm}$ depths .... 15

Figure 12 - Application of histogram equalization (a) Imaged area (b) Original reconstructed image (c) Image after histogram equalization ................................................................. 16 Figure 13 - Application of median filter (a) Image after histogram equalization (b) Image after noise (outliers) removal 17 Figure 14 - Application of thresholding (a) Imaged area of the plate (b) Parallel plane slice at 4mm depth after histogram equalization (c) Features of interest extracted by thresholding..... 18 


\section{List of Tables}

Table 1 - Parameters of X8500sc camera....................................................................... 7 


\section{Abstract}

Additive manufacturing (AM, or 3D printing) for commercial nuclear energy applications is an emerging method for cost-efficient manufacturing aimed at replacing aging nuclear reactor parts and reducing costs for new construction. Because of the geometry of metallic structures of interest for nuclear applications, which consist of planar primitives with no symmetry of revolution, limited options are available for non-destructive evaluation (NDE) either during or post manufacturing. Known material flaws in AM include low density regions consisting of nonsintered powder, which have to be detected to ensure the safety of long-term performance nuclear reactor components. As a solution to NDE of AM, we are developing pulsed thermal tomography (PTT) models and depth inversion algorithms for 3D imaging. PTT has many advantages because the method is non-contact and allows for in-service, NDE of AM nuclear reactor parts. By analyzing transients of surface temperature response due to internal thermal resistances, one can obtain 3D reconstructions of material effusivity using a unique inversion algorithm developed at Argonne. This study investigates the capability of PTT in imaging several AM structures fabricated from Inconel 718 (IN718) feedstock. The AM structures have complex geometry, but do not have calibrated internal defects. The objective is to determine PTT settings, such as the total integration time, for imaging of representative AM structures. A new FLIR X8500sc IR camera with higher spatial resolution $(1280 \times 1024$ at $181 \mathrm{~Hz}$ frame rate) was integrated into the PTT laboratory setup. Software tools were developed to ensure compatibility of new camera files with legacy effusivity reconstruction codes. The new camera was used to obtain 3-D reconstructions of IN718 nozzle plate and a particle filter plate. The results demonstrate the capability of PTT in 3D imaging of complex geometry AM structures. Further, increased resolution imaging is achieved compared to prior results using older FLIR SC4000 IR camera. In addition, preliminary studies were conducted on developing image processing algorithms for automated detection of flaws. Initial demonstrations are shown for segmentation of PTT images of flat bottom hole (FBH) specimens. Imaging of FBH specimens was described in a prior report. Intermediate results demonstrated in this report will be developed further in detection of flaws in AM specimens. 


\section{Introduction}

\subsection{Background}

Additive manufacturing (AM) for nuclear energy applications is an emerging method for costefficient manufacturing aimed at replacing aging nuclear reactor parts and reducing costs for new construction of advanced reactors [Bertali 2015, Freyer 2018]. However, there are still challenges for widespread deployment of AM in nuclear reactors, particular the ability to perform nondestructive evaluation (NDE) of AM parts. Because of the intrinsic features of AM process for fabricating stainless steel and nickel super alloys metallic parts, such as direct laser sintering (DLS), defects can appear consisting of low density regions or pores. Porosity can be introduced into AM parts due to incomplete melting of the powder particles or insufficient overlapping of the melt pools [Cunnigham 2017]. Oscillations in the surface of the melt pool caused by rapid heating and cooling result in powder ejection and splattering of the melt, resulting in surface roughness and porosity [Zhao 2017]. Furthermore, improper cooling rates can cause the formation of nonequilibrium phases and residual stresses, requiring post-process heat treatments [Kampen 2011, Sames 2016, Lewandowski 2016]. The pore is potentially a seed for crack formation in the structure due to non-uniform expansion of the material in response to thermal and mechanical stresses in nuclear reactor [Heifetz 2018, Wakamatsu 1995]. Pores have been observed in destructive examinations to be on the order of $20 \mu \mathrm{m}$ and larger.

Currently, there exist limited options for nondestructive examination (NDE) of AM structures either during or post-manufacturing. During manufacturing phase, spatial constraints of the 3-D printer limit deployment of many conventional NDE systems, such as radiography. Furthermore, in DLS manufacturing, a metallic part is covered by un-sintered powder. This prevents the use of contact methods, such as ultrasound, and obscures signals from non-contact methods, such as passive thermography. In post-manufacturing phase, complex shapes composed of planar geometrical primitives with lack of rotational symmetry make it difficult to perform digital radiography. Contact NDE techniques, such ultrasound, would be difficult because AM structures have rough surfaces which affects probe coupling. In addition, NDE methods such as ultrasound and eddy currents require time-consuming point-by-point raster scanning of specimens. As a solution to NDE of AM structures, Argonne is developing pulsed thermal tomography (PTT) models and depth inversion algorithms for 3D imaging and flaw detection. PTT obtains reconstruction of material internal defects by monitoring surface temperature transients following thermal pulse applied to material surface. The method is non-contact, with measurements performed from stand-off distance from one side of the specimen. An imaging camera with megapixel array of detector elements acquires an image of a large section of material. This allows for detection of flaws with minimal amount of mechanical scanning [Heifetz 2019a].

A schematic depiction of the PTT setup is shown in Figure 1. The method consists of illuminating material with white light flash lamp, which rapidly deposits heat on the material surface [Sun 2016, Sun 2014]. Heat transfer then takes place from the heated surface to the interior of the sample, resulting in a continuous decrease of the surface temperature. A megapixel fast frame infrared (IR) camera records time-resolved images of surface temperature distribution 
$T(x, y, t)$. The acquired thermal-imaging data therefore consist of a series of $2 \mathrm{D}$ images of the sample's surface temperature at consecutive time instants.

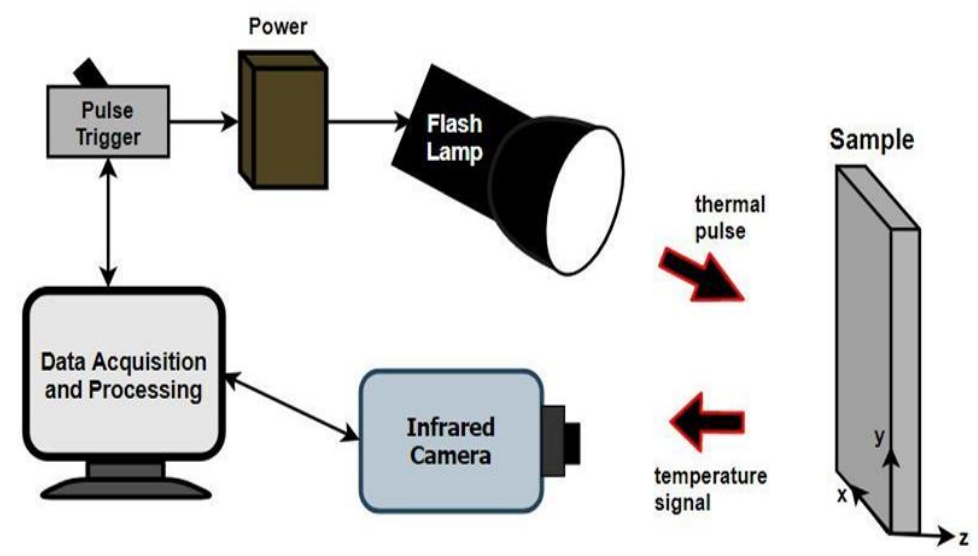

Figure 1 - Schematic diagram of pulsed thermal tomography system

The unique reconstruction algorithm of PTT developed at Argonne obtains thermal effusivity $\mathrm{e}(\mathrm{x}, \mathrm{y}, \mathrm{z})$ as a function from time-dependent surface temperature $\mathrm{T}(\mathrm{x}, \mathrm{y}, \mathrm{t})$ measurements. Effusivity is defined as $\mathrm{e}=(\rho \mathrm{ck})^{1 / 2}$ is a measure of how the material exchanges thermal energy with its surroundings. Reconstructed effusivity is obtained from measurements of surface temperature according to [Heifetz 2019b], where $\mathrm{z}$ is the depth coordinate related to time, $\mathrm{x}$ and $\mathrm{y}$ are coordinates in the transverse plane, and $\alpha=\mathrm{k} / \rho \mathrm{c}$ is thermal diffusivity. Here, $\mathrm{k}$ is thermal conductivity, $\rho$ is density, $\mathrm{c}$ is specific heat, and $\mathrm{Q}$ is the instantaneously deposited surface thermal energy density $\left(\mathrm{J} / \mathrm{m}^{2}\right)$. The spatial reconstruction of effusivity is given as a product of depth function $\mathrm{z}$ and time derivative of the inverse of surface temperature evaluated at time $\mathrm{t}$ corresponding to depth $\mathrm{z}$.

\subsection{Overview}

In this report, we describe the results of evaluation of the capability of PTT system in imaging of complex geometry AM metallic specimens. These specimens do not have calibrated internal defects. The objective of imaging is to determine PTT settings, such as the total integration time, to image several representative AM structures. The laboratory PTT system was upgraded with a new FLIR X8500sc imaging camera with higher spatial resolution and sensitivity. Using the new camera, IN718 nozzle plate and a section of a filter plate manufactured with DLS method were imaged. Reconstructions demonstrate that PTT is capable of imaging through all specimens. In addition, preliminary results on development of image processing algorithms for automated flaw detection in thermal tomography are described. Intermediate results presented in this reports will be developed further 


\section{Imaging of Additively Manufactured Structures with Complex Geometry}

Imaging of representative AM structures was performed to investigate optimal PTT settings and evaluate system performance.

\subsection{Pulsed Thermal Tomography System Upgrade}

To extend the capabilities of imaging AM metallic components, hardware and software of the laboratory PTT system was upgraded through supplemental equipment funding grant provided by Argonne National Laboratory. Hardware update consists of acquiring a new FLIR X8500sc midwave infrared (MWIR) imaging camera, operating in $3-5 \mu \mathrm{m}$ band with noise equivalent temperature difference (NETD) of 20mK. X8500sc model provides maximum spatial resolution of $1280 x 1024$, with frame rate at full window of $181 \mathrm{~Hz}$. The frame rate can be increased at the expense of reducing the viewing window, or equivalently reducing spatial resolution of the image. These performance parameters are superior to those of FLIR SC4000 MWIR camera used in previous generation PTT system are 320x256 spatial resolution with frame rate at full window of $420 \mathrm{~Hz}$ and NETD of $25 \mathrm{mK}$ [Heifetz 2019a]. Based on preliminary sensitivity considerations, higher spatial resolution and lower detection threshold of the new camera are expected to provide higher sensitivity in detection of flaws in AM specimens. Several configurations of the X8500sc camera (resolution, integration time and corresponding frame rate) we evaluated in imaging of flat bottom hole specimens [Heifetz 2019a]. Parameter values of X8500sc camera used in performance evaluation are shown in Table 1. Qualitative results indicate that camera settings with spatial resolution of $768 \times 520$ pixels with $216 \mathrm{~Hz}$ frame rate $(4.6 \mathrm{~ms}$ integration time). These are shown in boldface in Table 1 .

Table 1 - Parameters of X8500sc camera

\begin{tabular}{|c|c|c|}
\hline Resolution & $\begin{array}{c}\text { Integration Time } \\
(\mathbf{m s})\end{array}$ & $\begin{array}{c}\text { Frame Rate } \\
(\mathbf{H z})\end{array}$ \\
\hline $320 \times 256$ & 5 & 200 \\
\hline $640 \times 480$ & 4.6 & 216 \\
\hline $704 \times 512$ & 4.1 & 243 \\
\hline $\mathbf{7 6 8 \times 5 2 0}$ & $\mathbf{4 . 6}$ & $\mathbf{2 1 6}$ \\
\hline $1280 \times 1024$ & 5.5 & 181 \\
\hline
\end{tabular}

Integration of the new camera into PTT setup required upgrading software tools for file format conversion and compatability. In particular, interfacing with X8500sc camera is performed through FLIR Research IR ${ }^{\mathrm{TM}}$ software package, while the older SC4000 camera is controlled with FLIR Examine IR ${ }^{\mathrm{TM}}$ software package. The former software suit is not compatible with X8500sc camera. The challenge with using Research IR software package consisted of file compatibility with ANL effusivity reconstruction algorithm software. In the legacy Examine IR code, output files were generated in SFMOV format, which were converted with MATLAB script to a format 
readable by the effusivity reconstruction algorithm. Research IR can be used to convert the SEQ files created by the new X8500sc camera to SFMOV files. However, it exports the SFMOV files in a floating point format, but the legacy ANL code only supports the UInt16 format. The conversion algorithm, written in Python, reads the header of the exported SFMOV file to determine the data type (encoding) of the file and read various parameters needed for analysis. Since the legacy ANL code only supports data with UInt16 encoding, the program offers the user the option to convert the file if it is encoded in any other format. Furthermore, since the values of (signed) floating point data no longer match values of unsigned integer data, the script also rescales the data to fit the full UInt16 range by default, with an option for the user to select an alternate scaling range. The program then writes the file with modified headers to indicate UInt16. Finally, the program creates and executes batch files to call the legacy code with the appropriate parameters to perform the analysis. The graphical user interface (GUI) developed for file format conversion is displayed in Figure 2.

\begin{tabular}{|ll|}
\hline \multicolumn{1}{|l|}{ Convert } & \multicolumn{1}{l|}{. } \\
\hline x pixels & 640 \\
y pixels & 512 \\
frames & 452 \\
frame rate & 30.0 \\
int. time & 33.3 \\
flash frame & 0 \\
tau & 1.5 \\
incr & 0.5 \\
iwidth & 1 \\
iplot & 320 \\
jplot & 256 \\
Filename & Rec-000002.sfmov \\
Flt32 SFMov & $\square$ Convert to Ulnt16 \\
Scale & {$[0,65535]$} \\
& \\
\hline Select options & \\
\hline
\end{tabular}

Figure 2 - Screenshot of GUI for converting output of Research IR software to match file requirements of effusivity reconstruction code 


\subsection{Imaging Additively Manufactured IN718 Nozzle Plate}

Additively manufactured nozzle plate, fabricated by Westinghouse using IN718 feedstock was imaged with the new PTT system. The plate is $17 \mathrm{~mm}$ (2/3in) thick with approximately 8in by $8 \mathrm{in}$ cross-section. The imaging procedure was similar to that described in prior report [Heifetz 2019a]. The nozzle plate was imaged with $768 \times 520$ array of pixels with $216 \mathrm{~Hz}$ frame rate $(4.6 \mathrm{~ms}$ integration time per frame). A photograph of the PTT laboratory system for imaging of the nozzle plate with the new X8500sc camera integrated into the setup is shown in Figure 3. For better absorption of thermal energy, the imaged section of the plate was spay-painted with washable graphite paint. A photograph of the nozzle plate is shown in Figure 4(a), with highlighted section indicating area of the plate imaged with PTT is shown in Figure 4(b).

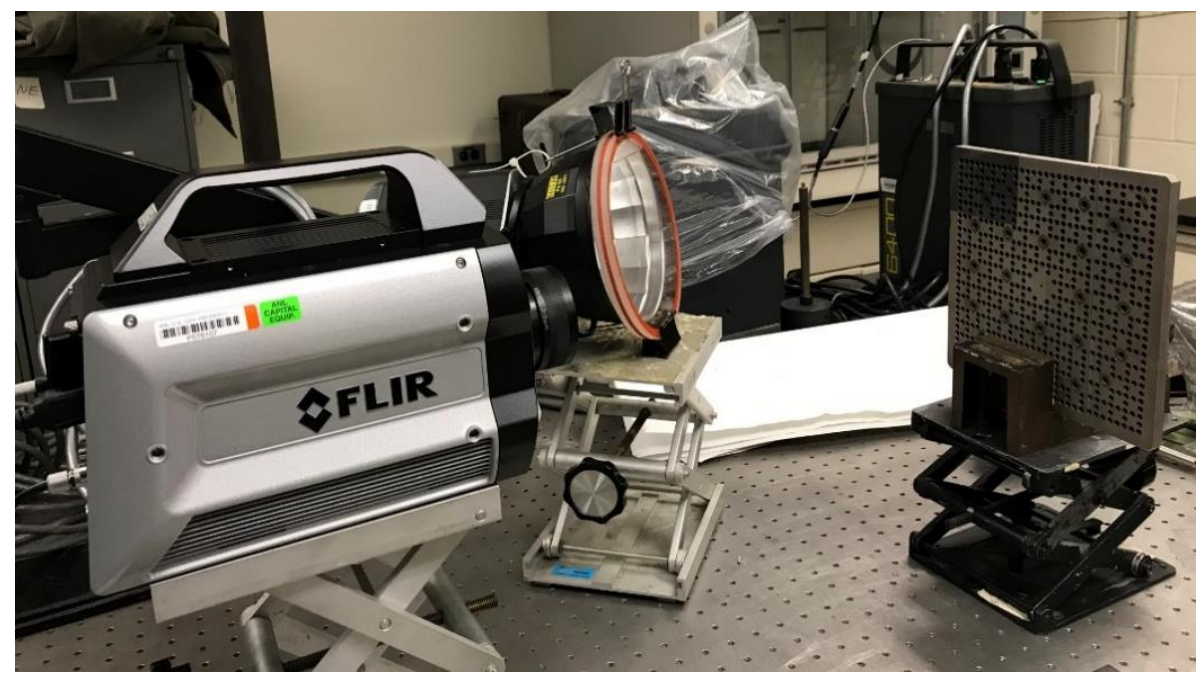

Figure 3 - Photograph of PTT setup imaging of IN718 nozzle plate with new FLIR X8500sc imaging camera

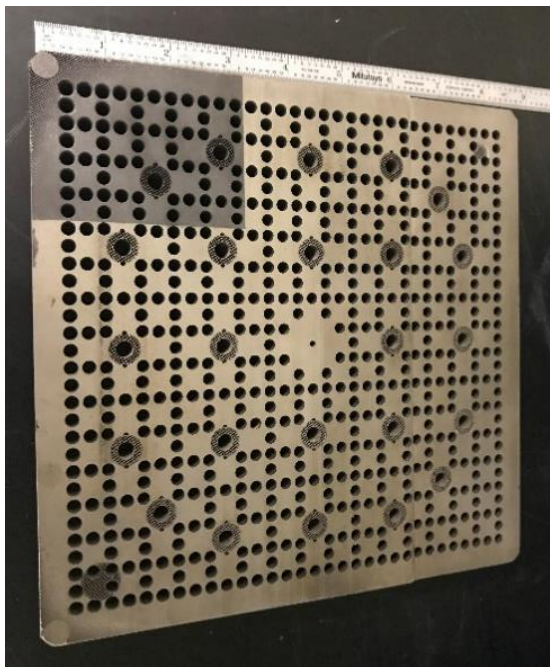

(a)

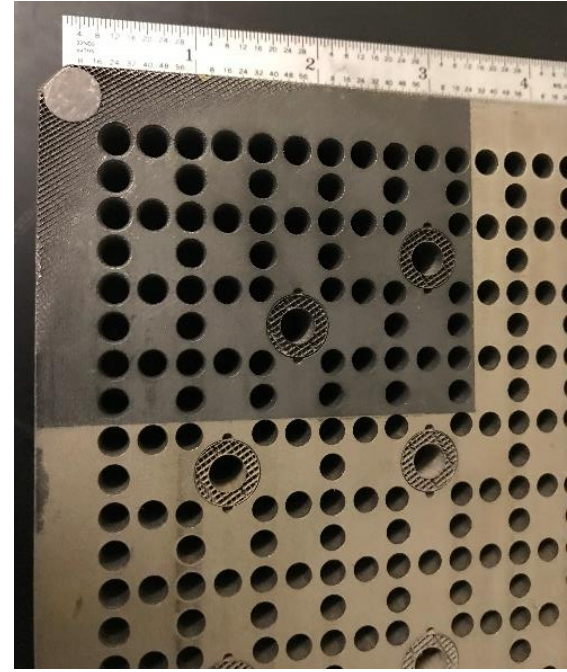

(b)

Figure 4 - (a) Photograph of the IN718 nozzle plate (b) Highlighted area imaged with PTT 
Transmission measurement determined thermal diffusivity of the nozzle plate to be $\alpha=6.25 \mathrm{~mm}^{2} / \mathrm{s}$. This number is larger than that for solid IN718 material $\left(\alpha=2.82 \mathrm{~mm}^{2} / \mathrm{s}\right)$ discussed in Section 4.3 . The explanation is that the through holes in the nozzle plate result in increased thermal diffusivity of the plate structure. We use the value of $\alpha=6.25 \mathrm{~mm}^{2} / \mathrm{s}$ for estimating depth of reconstructed parallel plane slices. Reconstruction slices at estimated depths of $0.67 \mathrm{~mm}, 1 \mathrm{~mm}, 1.2 \mathrm{~mm}$, and $1.35 \mathrm{~mm}$ are shown in Figure 5. The dark concentric circles in the figure correspond to spacer anchors, which are used for alignment of the plate during additive manufacturing process. Note that the level of details in reconstructed images is significantly better than similar images obtained with SC4000 IR camera [Heifetz 2019a].

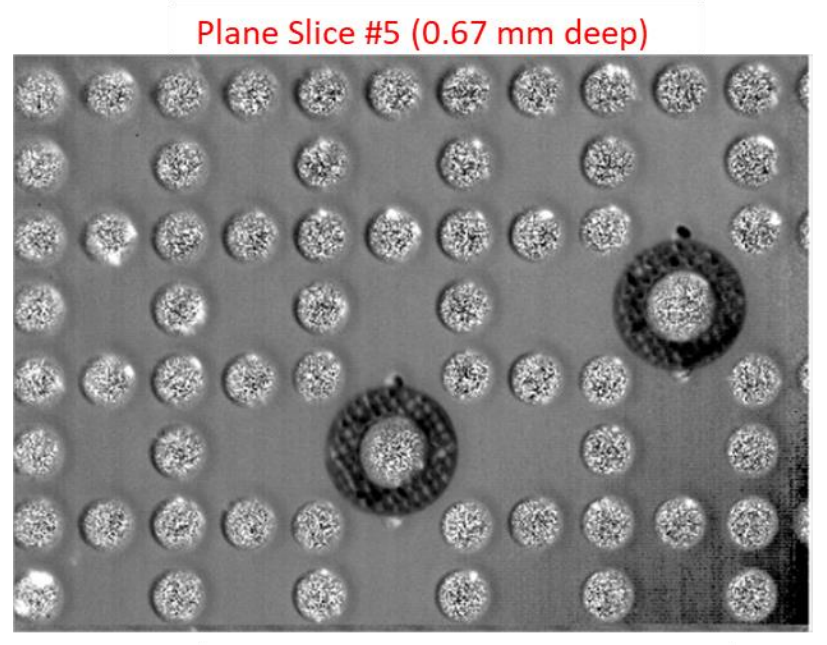

Plane Slice \#15 (1.2mm deep)

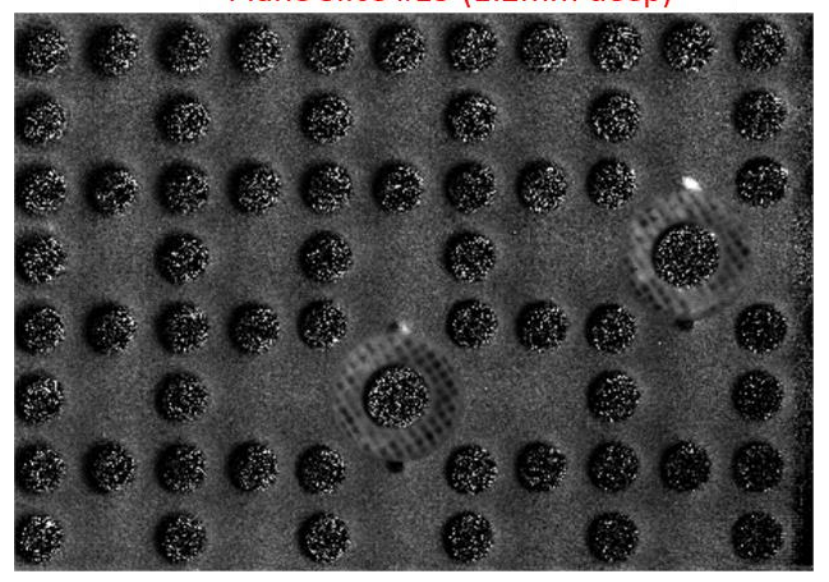

Plane Slice \#10 (1mm deep)

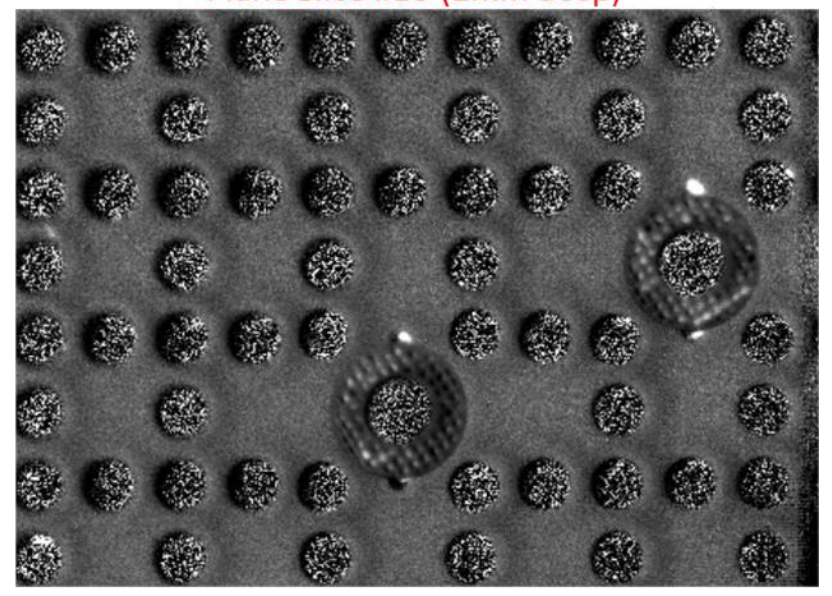

Plane Slice \#20 (1.35 $\mathrm{mm}$ deep)

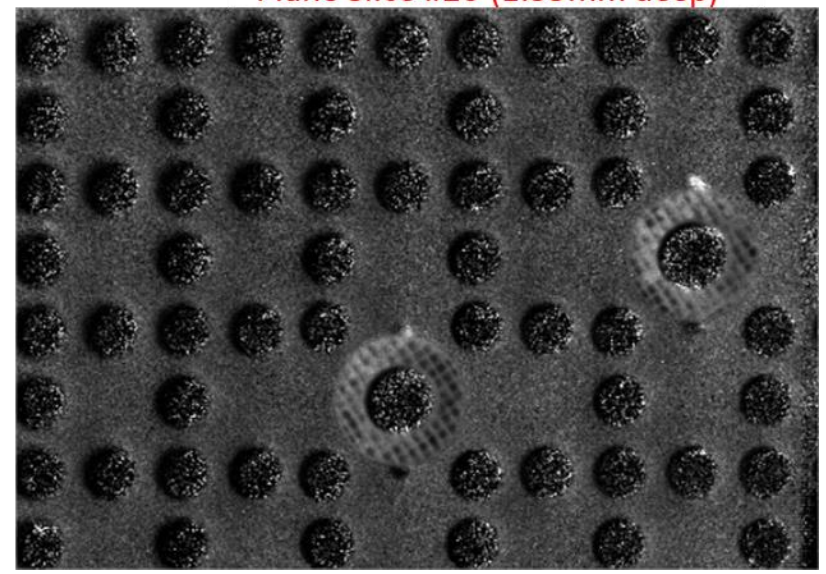

Figure 5 - Reconstruction of parallel slices of IN718 nozzle plate at $0.67 \mathrm{~mm}, 1 \mathrm{~mm}, 1.2 \mathrm{~mm}$, and $1.35 \mathrm{~mm}$ depths

Figure 6 shows reconstructions of horizontal and vertical slices side-by-side. The left plane of the figure shows a parallel plane reconstruction at $1.35 \mathrm{~mm}$ depth. Four horizontal lines labeled $\mathrm{j}=20$, $j=60, j=142$, and $j=224$ correspond to the indices of rows of the $758 \times 520$ array of pixels in the imaging camera. Vertical cross-section plane reconstructions corresponding to lines $\mathrm{j}=20,60,142$, 
and 224 are shown in the right plane of Figure 6 . The first image corresponding to $j=20$ line shows vertical cross-section profiles of equally spaced through-holes. The second image corresponding to $j=60$ line shows vertical cross-section profiles of a row of holes separated by a longer distance as compared to the holes in the first image. The third image corresponding to $j=142$ displays vertical and cross-sections of through-holes and a spacer at the right edge of the image. The fourth image corresponding to $\mathrm{j}=224$ line shows vertical cross-sections of through-holes and the spacer in the middle of the image. An important feature is that front top and back surfaces of the IN718 nozzle plate are distinguishable in all images. This shows that PTT is capable of imaging through $17 \mathrm{~mm}$ thick plate. Total imaging time was approximately $15 \mathrm{~s}$. Shorter imaging times resulted in cut-off view reconstructed images, while longer imaging time resulted in reconstructed images showing empty space below the back surface of the nozzle plate.

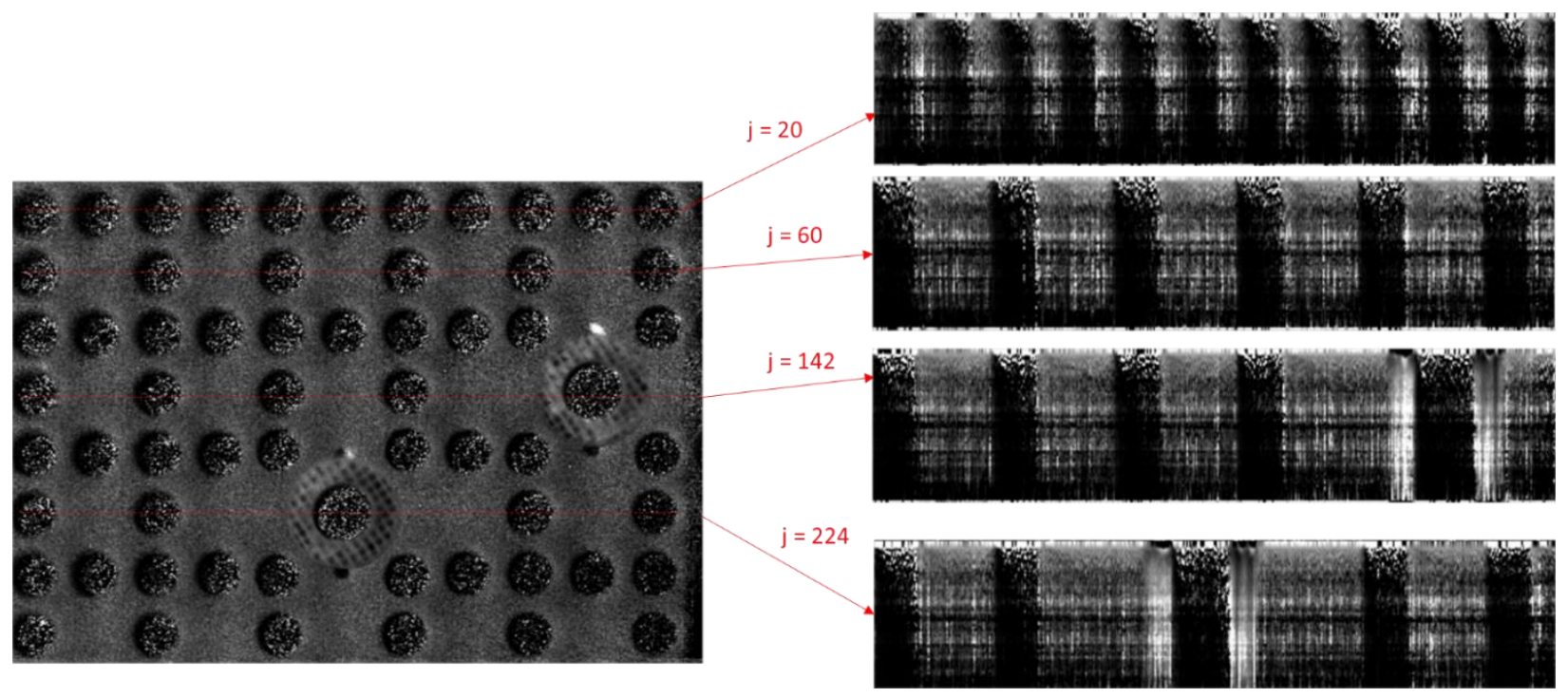

Figure 6 - Reconstruction of 3-D effusivity of IN718 nozzle plate (Left) Parallel slice at $1.35 \mathrm{~mm}$ depth (Right) Vertical cross-section slices

\subsection{Imaging Additively Manufactured IN718 Particle Filter Plate}

Additively manufactured particle filter plate for removing contaminations in the cooling fluid, fabricated by Westinghouse using DLS method using IN718 feedstock, was imaged with the new PTT system. A photograph of the PTT laboratory system for imaging of the nozzle plate with the new X8500sc camera integrated into the setup is shown in Figure 7. The section of the plate is approximately $3 \mathrm{in}$ by $3 \mathrm{in}$, with approximately $0.5 \mathrm{in}$ base height and a side piece of total height of approximately $1.5 \mathrm{in}$ and 0.2 in thickness. A photograph of the filter plate is shown in Figure 8 , where Figure 8(a) displays the top view, and Figure 8(b) displays the bottom/side view. The plate contains a number of through-penetrations, which in an actual filter plate would contains wires for trapping small particles, which are not part of the article in the imaging study. The imaging 
procedure was similar to that described in prior report [Heifetz 2019a]. The nozzle plate was imaged with $768 \times 520$ array of pixels with $216 \mathrm{~Hz}$ frame rate (4.6ms integration time per frame).

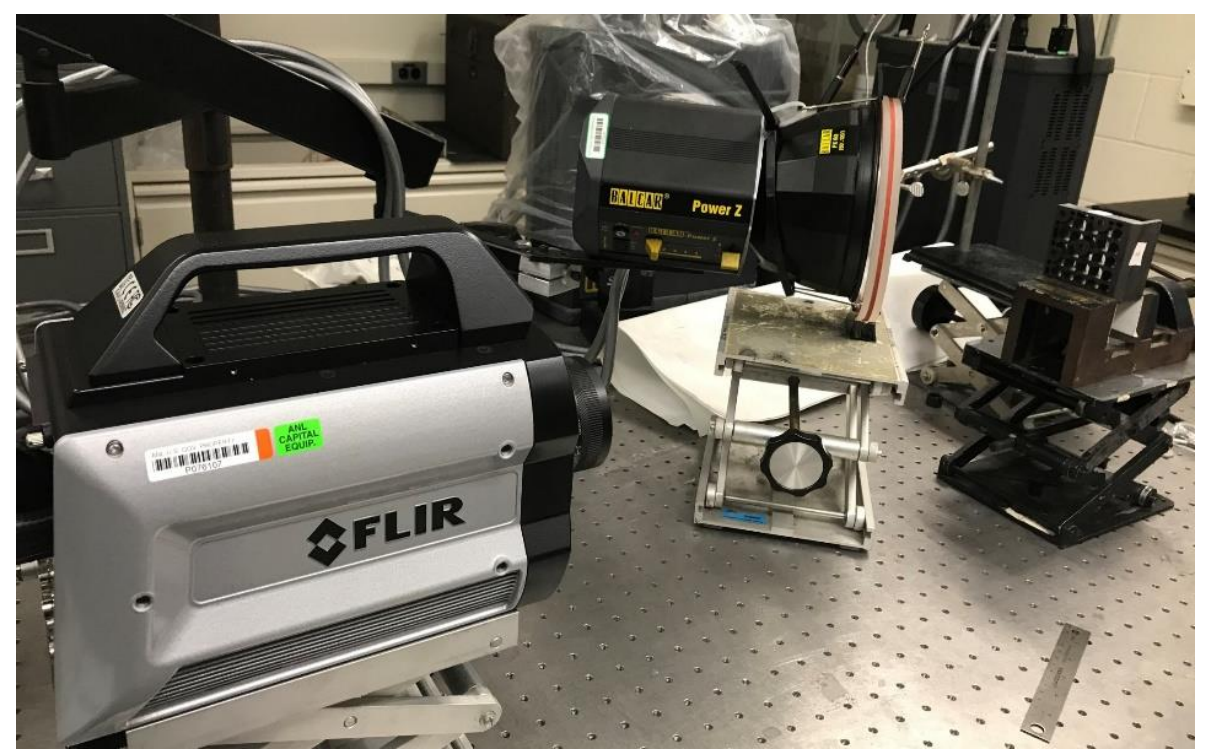

Figure 7 - Photograph of PTT laboratory setup for imaging of IN718 particle filter plate with new FLIR X8500sc imaging camera

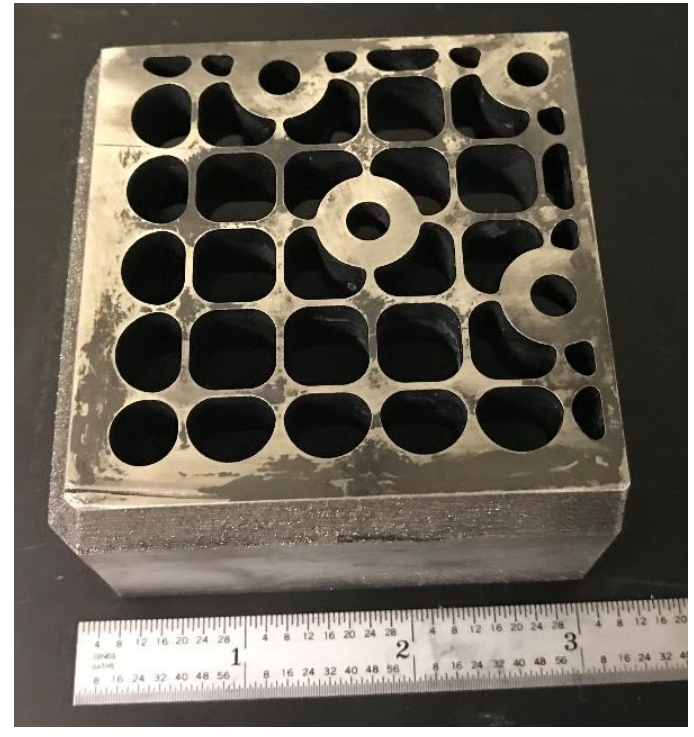

(a)

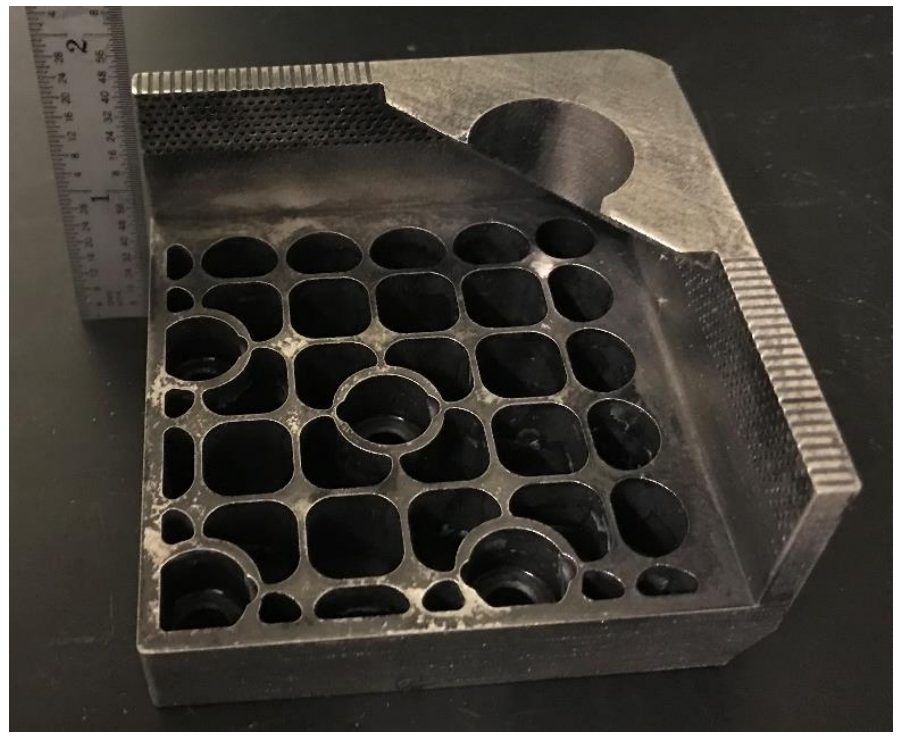

(b)

Figure 8 - Photograph of the filter plate (a) top view (b) bottom/side view

Because of the presence of large number of through-penetrations, thermal diffusivity of the filter plate is the same as that of the nozzle plate, $\alpha=6.25 \mathrm{~mm}^{2} / \mathrm{s}$. This value was used for depth estimation of reconstructions. The filter plate was first imaged through the top surface, shown in Figure 8(a). 
Parallel plane reconstruction slices at estimated depths of $1 \mathrm{~mm}, 1.35 \mathrm{~mm}, 1.65 \mathrm{~mm}$, and $1.9 \mathrm{~mm}$ are shown in Figure 9.

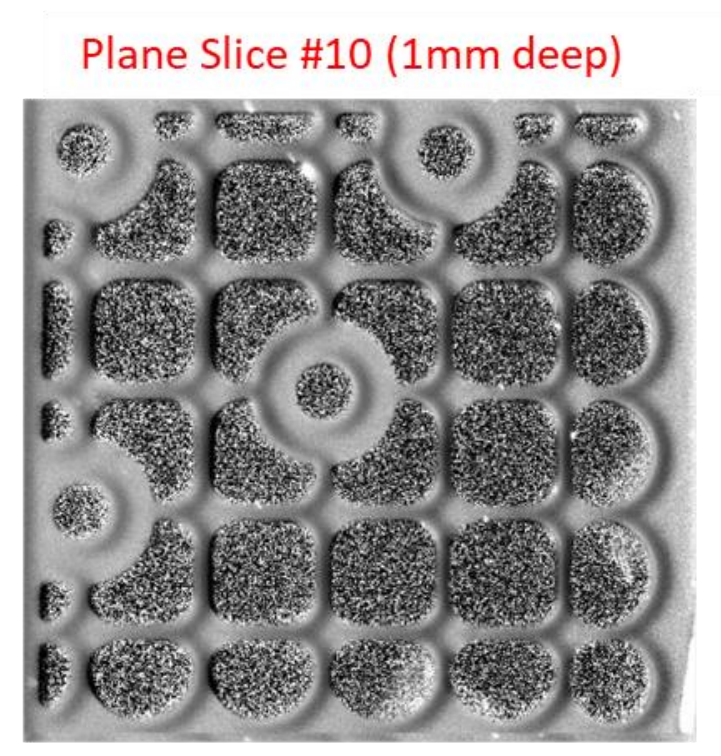

Plane Slice \#30 (1.65mm deep)

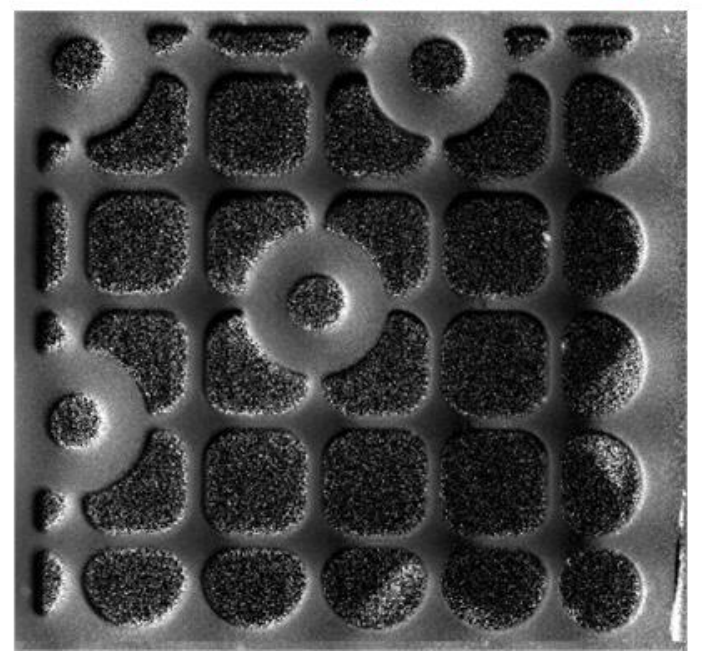

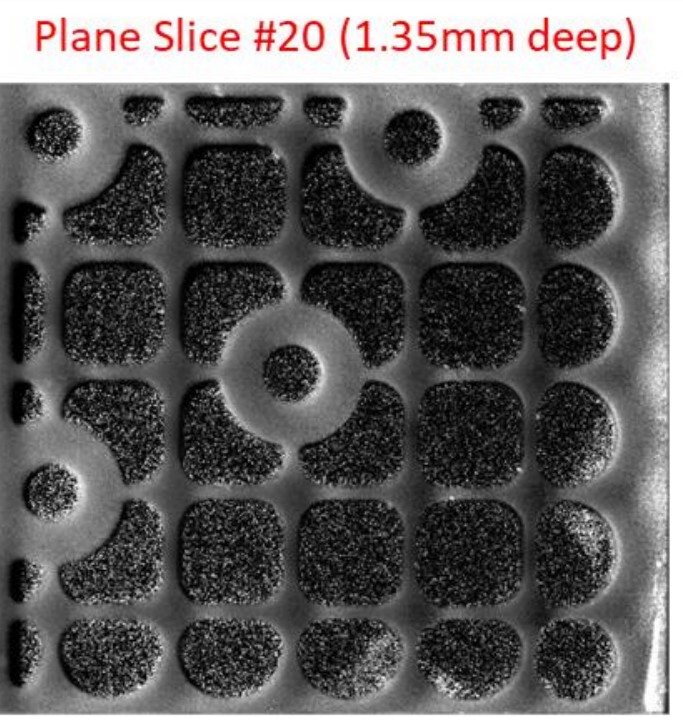

\section{Plane Slice \#40 (1.9mm deep)}

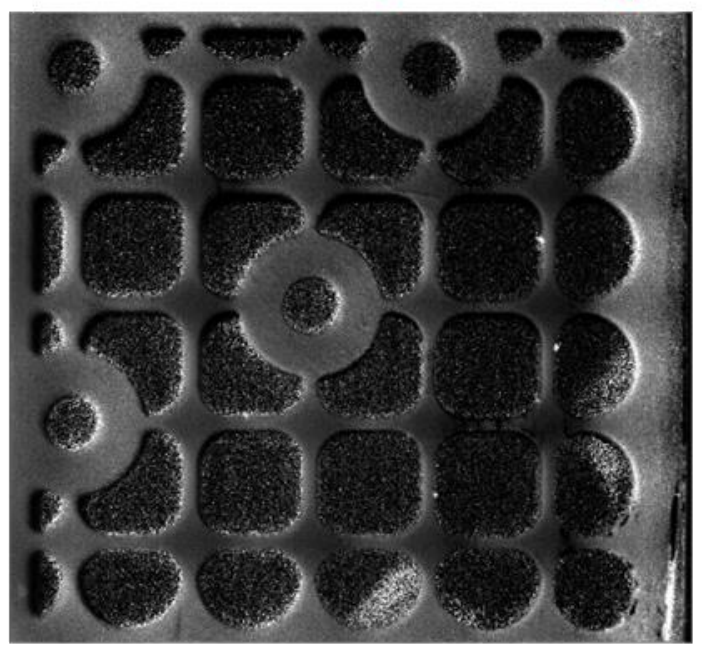

Figure 9 - Reconstruction of parallel slices of IN718 particle filter plate top face at estimated $1 \mathrm{~mm}, 1.35 \mathrm{~mm}, 1.65 \mathrm{~mm}$, and $1.9 \mathrm{~mm}$ depths

Figure 10 shows reconstructions of horizontal and vertical slices side-by-side. The left plane of the figure shows a parallel plane reconstruction at $1.9 \mathrm{~mm}$ depth. Four horizontal lines labeled $\mathrm{j}=14$, $j=45, j=56$, and $j=170$ correspond to the indices of rows of the $758 \times 520$ array of pixels in the imaging camera. Vertical cross-section plane reconstructions corresponding to lines $j=14,45,56$, and 170 are shown in the right plane of Figure 10. The first image corresponding to $j=14$ line shows vertical cross-section profiles near the edge of the plate. The second image corresponding to $j=45$ line shows vertical cross-section profiles of a section of the plate drawn mostly through 
solid material. The third image corresponding to $\mathrm{j}=56$ displays vertical and cross-sections of reconstructions of several through-holes. The fourth image corresponding to $j=170$ line shows vertical cross-sections of through-holes. As in the case of the nozzle plate, an important feature is that front top and back surfaces of the IN718 particle filter distinguishable in all images. Total imaging time was approximately 15s. Shorter imaging times resulted in cut-off view reconstructed images, while longer imaging time resulted in reconstructed images showing empty space below the back surface of the nozzle plate.
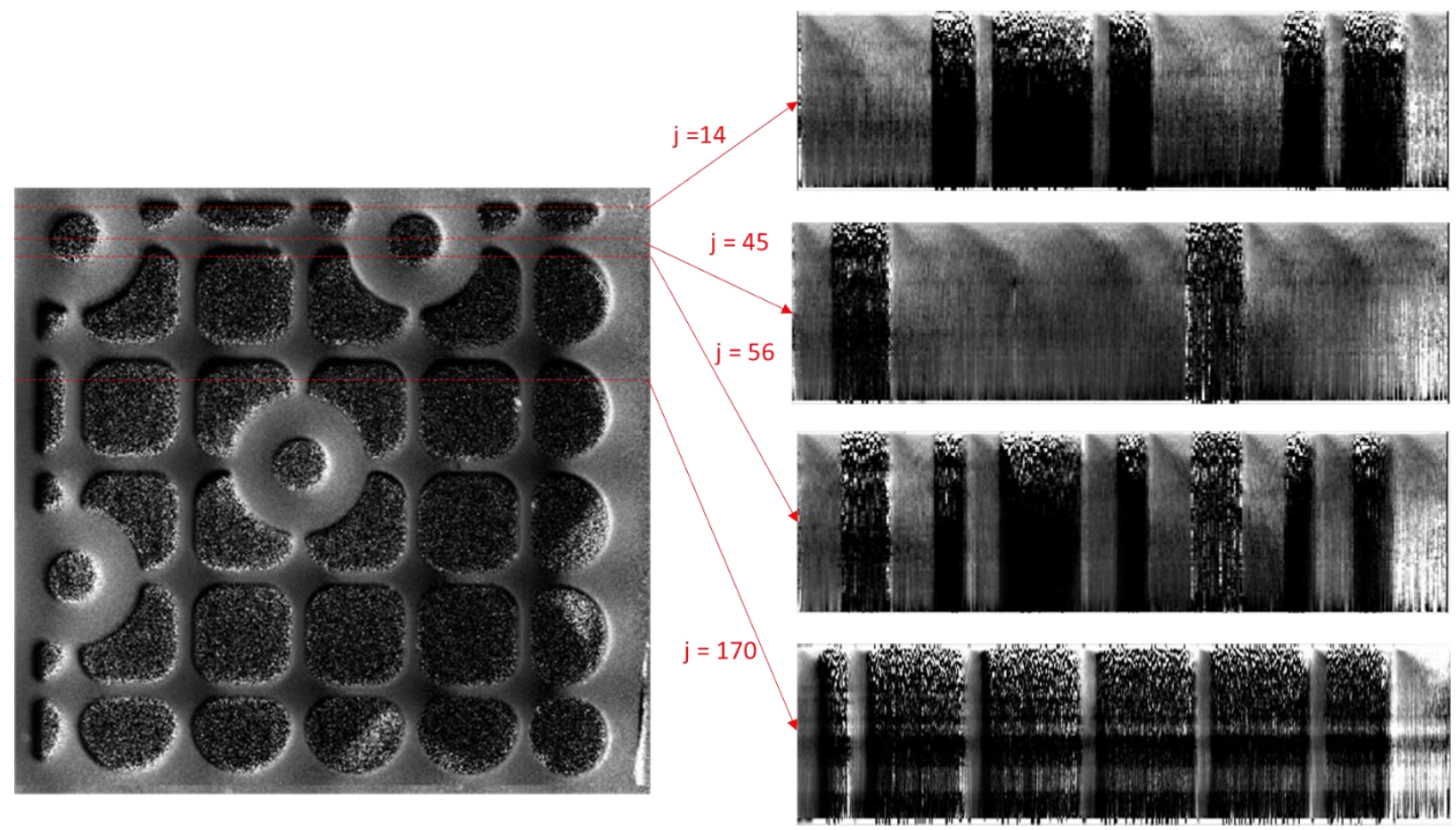

Figure 10 - Reconstruction of 3-D effusivity of IN718 filter plate (Left) Parallel slice at 1.9mm depth (Right) Vertical cross-section slices

Next, the particle filter plate was imaged through the solid side surface, as seen in Figure 8(b). For heat diffusion through mostly solid IN718, thermal diffusivity is $\alpha=2.82 \mathrm{~mm}^{2} / \mathrm{s}$. Parallel plane reconstruction slices at estimated depths of $0.75 \mathrm{~mm}, 0.9 \mathrm{~mm}, 1.1 \mathrm{~mm}$, and $1.3 \mathrm{~mm}$ are shown in Figure 11. Note that relevant information is contained only in the bottom and right side parts of the figure. The side section of the plate is approximately $3 \mathrm{~mm}$ thick. The images in Figure 11 are complimentary to those in the vertical cross-sections in the right panel of Figure 10, particularly reconstructions corresponding to $\mathrm{j}=14$ near the edge of the plate. Dark regions at the bottom of images appearing in reconstructions corresponding to greater depth in Figure 11 indicate throughholes in the filter plate. 
Plane Slice \#14 (0.75 mm deep)

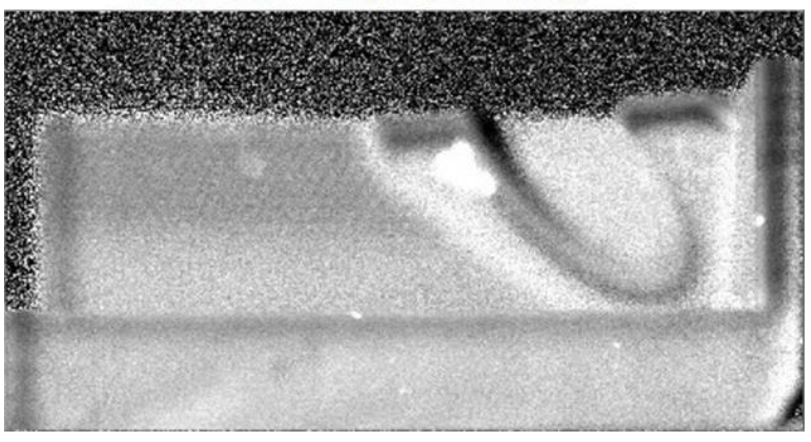

Plane Slice \#30 (1.1mm deep)

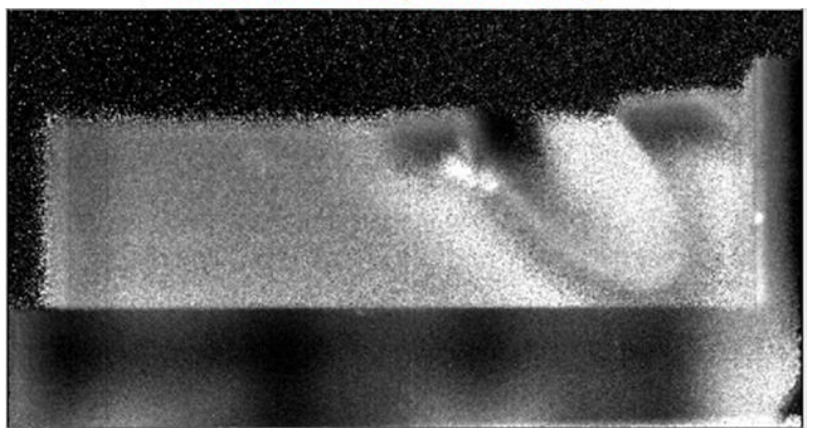

Figure 11 - Reconstruction of parallel slices of IN718 particle filter plate side face at estimated $0.75 \mathrm{~mm}, 0.9 \mathrm{~mm}, 1.1 \mathrm{~mm}$, and $1.3 \mathrm{~mm}$ depths
Plane Slice \#20 (0.9mm deep)

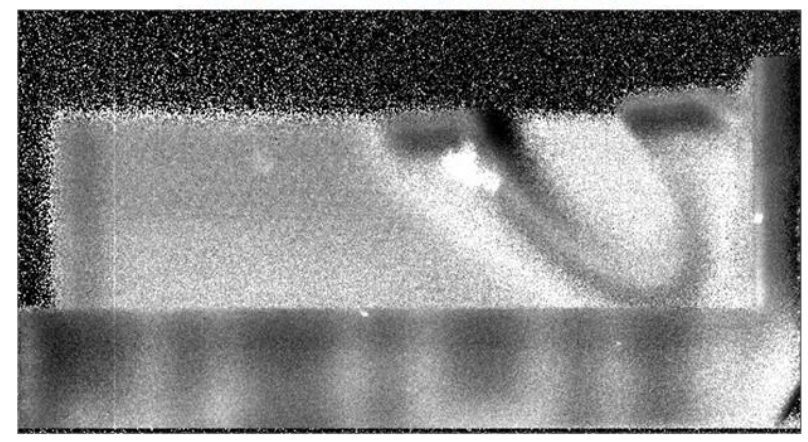

Plane Slice \#40 (1.3mm deep)

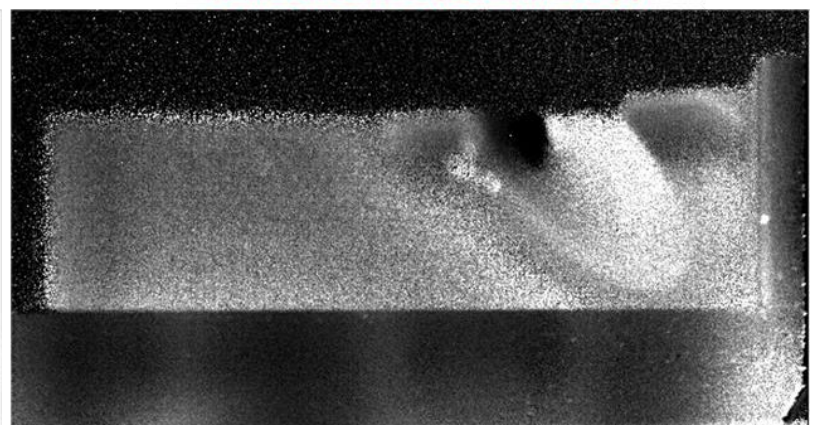




\section{Image Processing for Automated Detection of Defects}

As part of the effort towards development the capabilities for imaging of AM structures with PTT, we conducted preliminary studies of image processing. The objective is to improve the quality of images obtained with PTT, as well as to perform automated detection of flaws. Prior work on flaw detection used the model of flat bottom hole (FBH) simulated defects [Heifetz 2019a, 2019b]. In this report, we apply several image processing algorithms to FBH parallel slice reconstructions.

\subsection{Histogram Equalization}

During sampling, various frames have different contrast, affecting the representation of sample defects. A histogram equalization algorithm is used to enhance the contrast of the sample defect images so that calibrated defects are shown clearly. The algorithm consists in replacing the pixelvalues using a function designed to spread the repartition of the histogram. The function is given by the following equation:

$$
H(v)=\frac{C D F(v)-C D F_{\min }}{M \times N-C D F_{\min }} \times(L-1)
$$

In this equation above, $C D F(v)$ is the cumulative distribution function of pixels with value $v$ for calculating the equalized value $H(v) . M, N$ are respectively the numbers of rows and columns for each frame, $\mathrm{L}=256$ and represents the gray-scale range. Figure 12 demonstrates application of histogram equalization to an FBH parallel slice reconstruction obtained for a SS316 plate. Imaged area of the plate is shown in Figure 12(a). Figure 12(b) shows the reconstructed image of parallel slice at $1 \mathrm{~mm}$ depth. Figure 12(c) shows the image after application of histogram equalization, in which the contrast between features identifying FBH and the background is significantly enhanced.

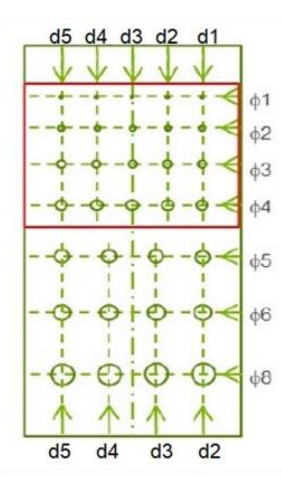

(a)

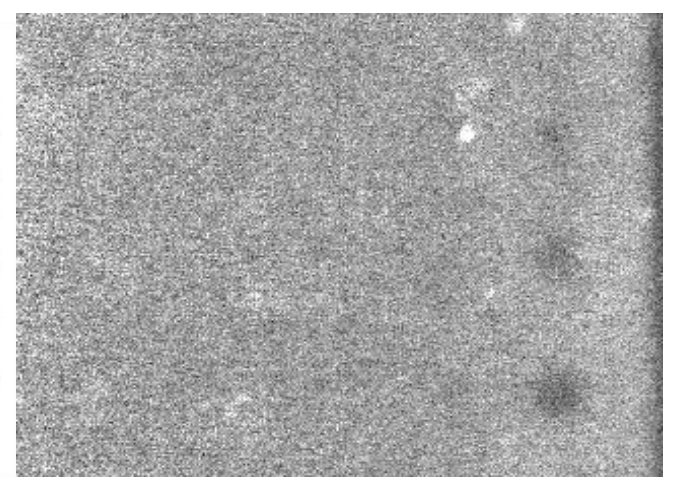

(b)

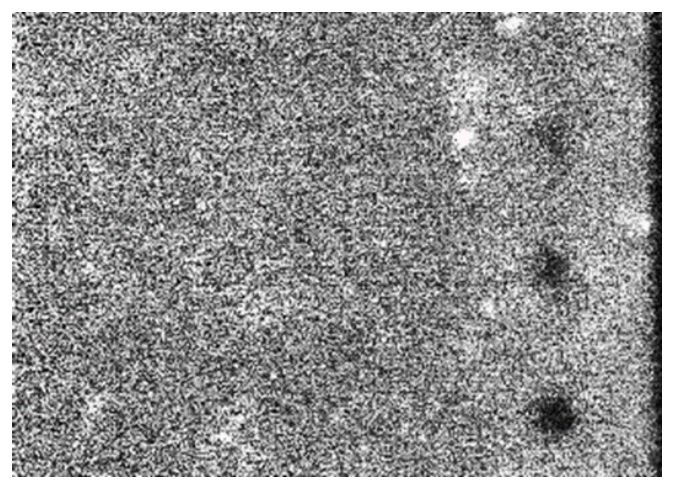

(c)

Figure 12 - Application of histogram equalization (a) Imaged area (b) Original reconstructed image (c) Image after histogram equalization 


\subsection{Median Filtering to Remove Noise}

Detection capability depends on signal to noise ratio of the feature of interest in the image. We briefly explore the use of a median filter to reduce signal noise in images obtained from imaging FBH specimen. The study used an image of SS16 plate with FBH. A selective median filter is used to replace a pixel by median of the pixels in the surrounding if it deviates from the median by more than a certain value (the threshold). Image obtained after histogram equalization in Figure 12(c) is repeated in Figure 13(a). In this example, the radius of the area is 35 pixels and the threshold is set at grayscale intensity level of 100 (grayscale intensity range is from 0 to 255). As can be seen in the processed image shown in Figure 13(b), outliers (white pixel noise) are filtered and calibrated FBH defects can be observed more clearly.

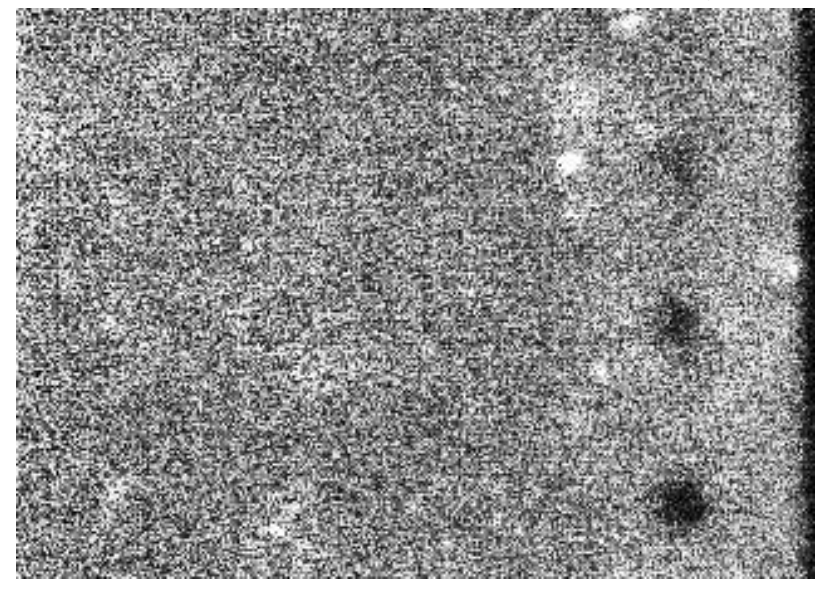

(a)

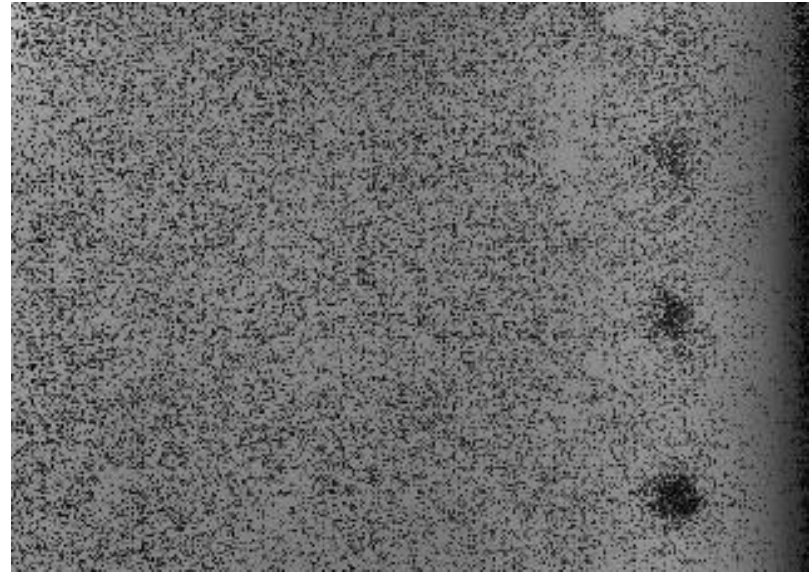

(b)

Figure 13 - Application of median filter (a) Image after histogram equalization (b) Image after noise (outliers) removal

\subsection{Segmentation of Defects by Thresholding}

Automated extraction of flaws from the image can be achieved through segmentation and labeling. Thresholding method is used to segment the calibrated defects from the background while removing image noises. Minimum and maximum pixel area size are applied to exclude anything that is not an object of interest in the image, thus labeling the calibrated defects. Roundness values between 0.0 and 1.0 is used to help exclude unwanted objects. Then selecting the labeled regions with edge only for each region, removing the unwanted objects (noises) for convenient measurements. Application of threshold to segmentation of FBH features in the image is shown in Figure 14. Imaged area of the SS316 plate is shown in Figure 14(a). Figure 14(b) shows the reconstructed image of parallel slice at $4 \mathrm{~mm}$ depth after application of histogram equalization procedure described above. Figure 14(c) shows thresholded and extracted features of interest corresponding to FBH's. Further work will explore application of machine learning to feature extraction [Luo 2019]. 


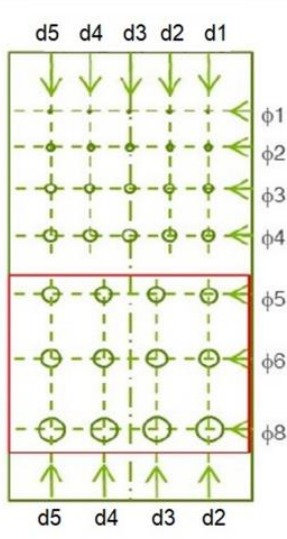

(b)

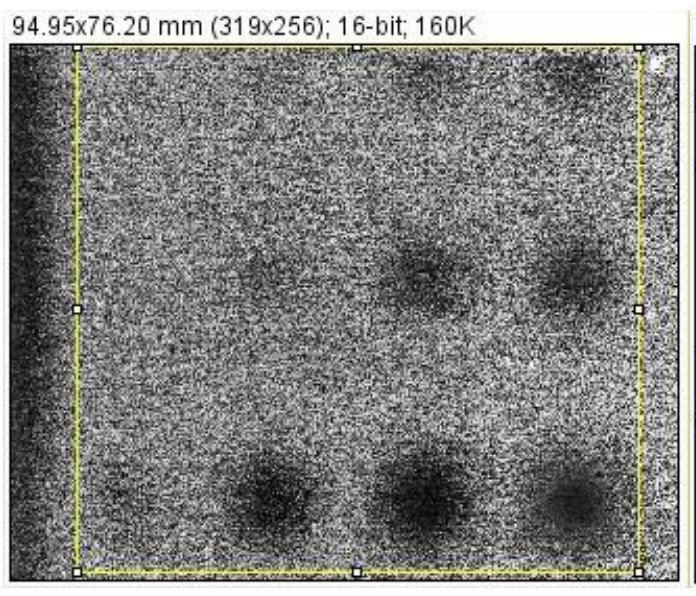

(b)

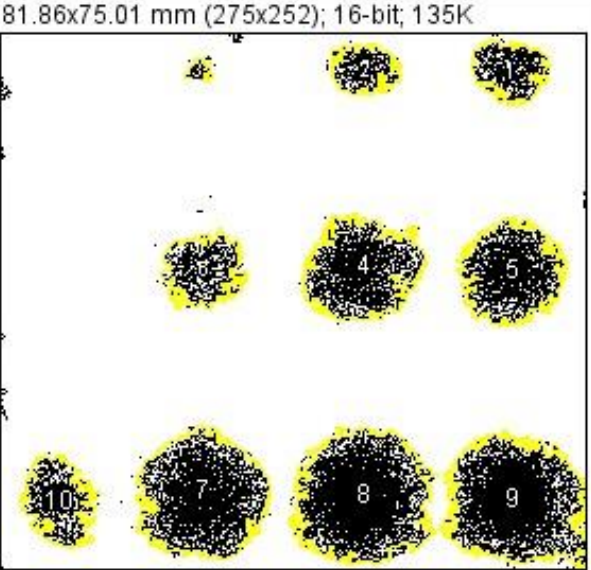

(c)

Figure 14 - Application of thresholding (a) Imaged area of the plate (b) Parallel plane slice at $4 \mathrm{~mm}$ depth after histogram equalization (c) Features of interest extracted by thresholding 


\section{Conclusions}

This report investigated the capability of PTT in imaging several AM structures fabricated from Inconel 718 (IN718) feedstock. The AM structures in this study do not have calibrated internal defects. The objective is to determine PTT settings, such as the total integration time, for imaging of representative AM structures. A new FLIR X8500sc IR camera with higher spatial resolution $(1280 \times 1024$ at $181 \mathrm{~Hz}$ frame rate) was integrated into the PTT laboratory setup. Software tools were developed to ensure compatibility of new camera files with legacy effusivity reconstruction codes. The new camera was used to obtain 3-D reconstructions of IN718 nozzle plate and a particle filter plate. The results demonstrate the capability of PTT in 3-D imaging of complex geometry AM structures. Further, increased resolution imaging is achieved compared to prior results using older FLIR SC4000 IR camera. In addition, preliminary studies were conducted on developing image processing algorithms for automated detection of flaws. Initial demonstrations are shown for segmentation of PTT images of flat bottom hole (FBH) specimens. Imaging of FBH specimens was described in a prior report. Intermediate results demonstrated in this report will be developed further in detection of flaws in AM specimens. Next phase of the project work will investigate detection of defects imprinted in AM specimens. Machine learning algorithms for feature detection and extraction will be studied in parallel. 


\section{References}

Bertali, G., Wang, Y., Lim, J., Scenini, F., Long, C., Freyer, P., and Burke, M. (2015). "Microstructural Analysis of 3D-Printed Alloy 718," Microscopy and Microanalysis, 21(S3), 463-464.

Cunningham, R., Narra, S. P., Montgomery, C., Beuth, J., \& Rollett, A. D. (2017). Synchrotronbased X-ray microtomography characterization of the effect of processing variables on porosity formation in laser power-bed additive manufacturing of Ti-6Al-4V. Jom, 69(3), 479-484.

Freyer, P.D., Cleary, W.T., Ruminski, E.M., Long, C.J., Xu, P. (2018). "Hot Cell Tensile Testing of Neutron Irradiated Additively Manufactured Type 316L Stainless Steel," Proceedings of the 18th International Conference on Environmental Degradation of Materials in Nuclear Power Systems -- Water Reactors: Volume 1, 1021-1038.

Heifetz A., Lisowski D., Weathered M., Momozaki Y., Chien H.T., Bakhtiari S. (2018) "Preliminary Review Analysis of Distributed Sensors for Versatile Test Reactor (VTR) Environment," Argonne National Laboratory, ANL/NSE-18/11.

Heifetz A., Sun J.G., Elmer T., Shribak D., Saboriendo B., Kozak P., Bakhtiari S., Cleary W., Khaykovich B. (2019a). "PTT System Performance Evaluation in 3-D Imaging of Calibrated Defects," Argonne National Laboratory, ANL-19/12.

Heifetz A., Liu T., Shribak D. (2019b) "PTT System Design and Data Analysis for Improved Performance," Argonne National Laboratory, ANL-19/25.

Kempen, K., Yasa, E., Thijs, L., Kruth, J. P., \& Van Humbeeck, J. (2011). Microstructure and mechanical properties of Selective Laser Melted 18Ni-300 steel. Physics Procedia, 12, 255263.

Lewandowski, J. J., \& Seifi, M. (2016). Metal additive manufacturing: a review of mechanical properties. Annual Review of Materials Research, 46, 151-186.

Luo, Q., Gao B., Woo W.L., Yang. Y. (2019). "Temporal and spatial deep learning network for infrared thermal defect detection,” NDT\&E International 108, 102164.

Sames, W. J., List, F. A., Pannala, S., Dehoff, R. R., \& Babu, S. S. (2016). The metallurgy and processing science of metal additive manufacturing. International Materials Reviews, 61(5), 315-360.

Sun J.G. (2016). "Quantitative three-dimensional imaging of heterogeneous materials by thermal tomography," Journal of Heat Transfer 138, 112004.

Sun J.G. (2014). "Pulsed thermal imaging measurement of thermal properties for thermal barrier coatings based on a multilayer heat transfer model," Journal of Heat Transfer 136, 081601.

Wakamatsu M., Nei H., and Hashiguchi K., (1995), "Attenuation of temperature fluctuations in thermal striping," J. Nucl. Sci. Technol., vol. 32, no. 8, pp. 752-762.

Zhao, C., Fezzaa, K., Cunningham, R. W., Wen, H., Carlo, F., Chen, L., \& Sun, T. (2017). Realtime monitoring of laser powder bed fusion process using high-speed X-ray imaging and diffraction. Scientific reports, 7(1), 3602. 


\section{Argonne}

Nuclear Science and Engineering (NSE) Division

Argonne National Laboratory

9700 South Cass Avenue, Bldg. 208

Argonne, IL 60439

www.anl.gov

Argonne National Laboratory is a U.S. Department of Energy laboratory managed by UChicago Argonne, LLC 